\title{
Preparation and Characterization of Amorphous B Powders by Salt-Assisted SHS Technique
}

\author{
Yujing Ou, ${ }^{1,2}$ Peiqing La, ${ }^{1}$ Dandan $\mathrm{Zhu}^{2}$ and Yalong $\mathrm{Zhu}^{2}$ \\ ${ }^{1}$ State Key Laboratory of Advanced Processing and Recycling of Non-Ferrous Metals, Lanzhou University of Science and Engineering, \\ Lanzhou, Gansu 730050, China \\ ${ }^{2}$ School of Petrochemical Engineering, Lanzhou University of Science and Engineering, Lanzhou, Gansu 730050, China
}

Correspondence should be addressed to Peiqing La; pqla@lut.cn

Received 21 July 2015; Revised 9 November 2015; Accepted 11 November 2015

Academic Editor: Fernando Lusquiños

Copyright (C) 2015 Yujing Ou et al. This is an open access article distributed under the Creative Commons Attribution License, which permits unrestricted use, distribution, and reproduction in any medium, provided the original work is properly cited.

\begin{abstract}
To use the salt-assisted SHS technique to prepare B powders was proposed. Calculation results found that the adiabatic combustion temperature of the $\mathrm{B}_{2} \mathrm{O}_{3}-\mathrm{Mg}$ reaction system was $2604 \mathrm{~K}$, higher than the $1800 \mathrm{~K}$ criterion of self-propagating temperature, which meant that the SHS application was feasible. When $0,10 \%, 20 \%, 30 \%, 40 \%, 50 \%$, and $60 \% \mathrm{NaCl}$ content were added, the adiabatic combustion temperature of the reaction system decreased linearly. When $60 \% \mathrm{NaCl}$ content was added, the adiabatic combustion temperature was $1799 \mathrm{~K}$ (lower than $1800 \mathrm{~K}$ ), unsuitable for self-propagating reaction, which was consistent with the experimental results. Through scanning electron microscope (SEM), energy disperse spectroscopy (EDS), and particle size analysis, the influence of different addition of $\mathrm{NaCl}$ on the morphology, average particle size, and purity of prepared B powder was investigated. EDS and chemical analysis indicated that the purity of prepared B powder was over $96 \%$ and the average particle size was within the range of $0.4 \sim 0.8 \mu \mathrm{m}$ when the content of $\mathrm{NaCl}$ was $50 \%$. The analysis of X-ray diffraction (XRD) and selected area electron diffraction (SAED) proved that the prepared B powder was amorphous.
\end{abstract}

\section{Introduction}

Amorphous boron is attractive material with applications in fuel additives $[1,2]$, dopant in solar cell $[3,4]$, and boron neutron capture therapy $[5,6]$. In particular, amorphous boron is a very interesting material as a fuel additive because it has high mass and volume specific combustion energy $[7,8]$.

Traditional methods to prepare amorphous boron powder include molten salt electrolysis, diborane pyrolysis, boron hydrogen chloride reduction, and magnesium thermal reduction [9]. With the potassium chloride-potassium fluoroborate-boron oxide molten salt system, Song et al. [10] succeeded in preparing the boron powder with the purity over $90 \%$. However, due to the limitations of low current use efficiency, poor working conditions, and discontinuous production, the molten salt electrolysis process failed to get any further development. Moreover, even though the diborane pyrolysis process and the boron hydrogen chloride reduction process can obtain boron high purity powder, the highly demanding working conditions and serious pollution problems limit the applications of these methods. At present, boron powder with the content of boron less than $90 \%$ and the particle size above $2 \mu \mathrm{m}$ can be only obtained by the metal thermal reduction, due to technical limitations [11-15].

SHS (self-propagating high-temperature synthesis) is a self-propagating process to realize reactions between the powders, which shortens and simplifies the procedures in comparison to traditional preparation processes. Once being started via ignition, no more outside energy is needed. Compared to other processes, this self-propagating technique has many advantages, such as simple process, high purity, small particle size, and high activity of product.

A new technique was proposed in this paper to produce boron powder and optimize the preparation process by combining the SHS technique and the traditional magnesium thermal reduction method and choosing $\mathrm{NaCl}$ as a diluter. The adiabatic temperature of SHS technique is rather high. The reaction occurs in a high-temperature state for a long time, which is liable to bring about the side reactions, reduce purity, and lead to particle aggregation. $\mathrm{NaCl}$ can effectively 
reduce the adiabatic combustion temperature, suppress side reactions, increase product purity, and reduce particle size. Moreover, the process is easier to be applied and realize industrialization. In this paper, effect of $\mathrm{NaCl}$ addition on morphology, size, and phase of submicron amorphous boron powders was investigated.

\section{Experiment}

2.1. Preparation of Samples. Commercial grade $\mathrm{B}_{2} \mathrm{O}_{3}$ (>99.0 wt\%, Liaoning Pengda Science and Technology Ltd., Yingkou), Mg (99.5 wt\%, Kunshan Fuerbang New Material Technology Co., Ltd., Kunshan), and $\mathrm{NaCl}$ (99.0 wt\%, Nanjing Dongde Chemical Technology Co., Ltd., Nanjing) were mixed in certain proportion. Materials were thoroughly mixed by a planetary ball mill and pressed into a cylinder. The tabletting pressure was $10 \mathrm{Mpa}$. A self-made reactor was used to successfully produce the ultrafine boron powders via the salt-assisted SHS technique. The combustion synthesis of the $60 \% \mathrm{NaCl}$ system was also tried in the experiment, which however resulted in incomplete reaction.

The main equation of combustion synthesis is as follows:

$$
\mathrm{B}_{2} \mathrm{O}_{3}+3 \mathrm{Mg}+k \mathrm{NaCl}=\mathrm{B}+3 \mathrm{MgO}+k \mathrm{NaCl}
$$

$k$ refers to the percentage of $\mathrm{NaCl}$ among all ingredients; $k$ is $0,10 \%, 20 \%, 30 \%, 40 \%, 50 \%$, and $60 \%$, respectively. The content of $\mathrm{Mg}$ in the reaction materials was in excess of $10 \%$.

If no $\mathrm{NaCl}$ was added in the reaction materials, the product obtained after combustion was relatively hard and needs grinding. This was because, without $\mathrm{NaCl}$, severe agglomeration occurred. If $\mathrm{NaCl}$ was added, the product obtained was a fluffy, block-like material. This was because the product was coated by $\mathrm{NaCl}$ and thus easy to crush. The obtained products contained boron powder, diluter $\mathrm{NaCl}$, byproduct $\mathrm{MgO}$, and so forth. The acid leaching-alkali leaching-acid leaching-water leaching process was adopted to produce high purity boron powder. The leaching agents included $\mathrm{HCl}, \mathrm{NaOH}$, and distilled water. After filtration and drying, the amorphous B powder was finally obtained.

The leaching reaction equation is as follows:

$$
\begin{gathered}
\mathrm{HCl}+\mathrm{MgO}=\mathrm{MgCl}_{2} \\
6 \mathrm{NaOH}+\mathrm{B}_{2} \mathrm{O}_{3}=2 \mathrm{Na}_{3} \mathrm{BO}_{3}+3 \mathrm{H}_{2} \mathrm{O}
\end{gathered}
$$

2.2. Analytical Methods. The morphology and elementary composition of B powder were examined by scanning electron microscope (JSM-6700, JEOL) equipped with an energy dispersive spectrometer (EDS) and chemical analysis. The phase analysis of the powder samples was investigated by $\mathrm{X}$-ray diffraction (XRD, D/max-2400, Rigaku) and selected area electron diffraction (SAED, JEM-1200EX, FEI USA). The average particle size of sample was measured by laser particle size analyzer (Nano Series Nano-ZS, ZETASIZER).

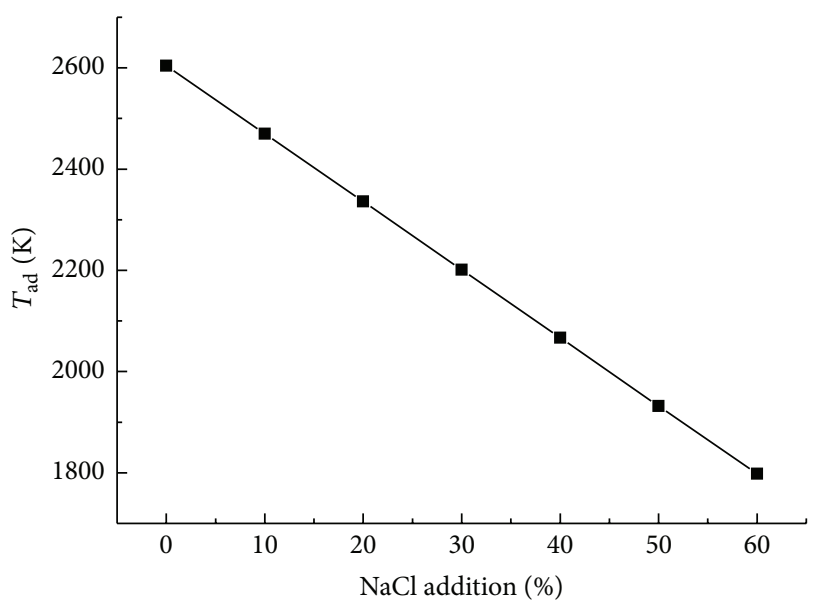

FIGURE 1: Change of $T_{\text {ad }}$ with the addition of $\mathrm{NaCl}$.

\section{Results and Discussion}

3.1. Calculations of Adiabatic Temperature. Adiabatic temperature $\left(T_{\mathrm{ad}}\right)$, thermodynamic parameter to describe the SHS characteristics, can not only serve as a criterion to judge whether reactions can occur, but also forecast the state of combustion products and provide a reference for the ingredient design of the reaction system. Merzhanov et al. proposed that only when $T_{\text {ad }}>1800 \mathrm{~K}$, can SHS reaction be completed. Otherwise, the combustion wave of the reaction system cannot propagate.

$T_{\mathrm{ad}}$ is calculated as follows: the adiabatic temperature of reaction (1) was $T_{\mathrm{ad}}$, and the cycle test algorithm was used [16]. If the temperature obtained after cycle test calculation is a phase-transition temperature, namely, $T=T_{\text {tr }}$, we need to judge the phase changes of the material [17]. The $C$ language was used to write a program to calculate the relationship between the addition of $\mathrm{NaCl}$ and $T_{\mathrm{ad}}$ of the reaction system via the cycle test algorithm. During the calculation, relevant thermodynamic data of reactants and products were derived from literature [18].

Figure 1 shows the calculated $T_{\text {ad }}$ with different $k$ values. As can be seen from Figure 1, with the increase of $k, T_{\text {ad }}$ demonstrates a linearly decreasing trend. As $\mathrm{NaCl}$ content increased from 0 to $50 \%$, the calculated $T_{\text {ad }}$ was higher than the criterion of self-propagating combustion temperature, namely, $1800 \mathrm{~K}$. Therefore, it was feasible to use the saltassisted SHS reaction. When the addition of $\mathrm{NaCl}$ was over $60 \%$, the calculated $T_{\text {ad }}$ was $1798 \mathrm{~K}$, less than $1800 \mathrm{~K}$, not feasible for self-propagating reaction. This was consistent with experimental results.

The $\mathrm{NaCl}$ melting point is $800.8^{\circ} \mathrm{C}$, lower than the calculated adiabatic temperature. $\mathrm{NaCl}$ is in liquid state in reaction. It absorbs heat in the melting process, so the addition of $\mathrm{NaCl}$ can help in reducing $T_{\text {ad }}$. The melting points of reactants and products are shown in Table 1.

According to the measurement of the adiabatic temperature and the initial reaction temperature, the initial reaction temperature of $\mathrm{B}_{2} \mathrm{O}_{3}-\mathrm{Mg}-\mathrm{NaCl}$ system was higher than the melting points of $\mathrm{B}_{2} \mathrm{O}_{3}, \mathrm{Mg}$, and $\mathrm{NaCl}$. We can therefore infer 


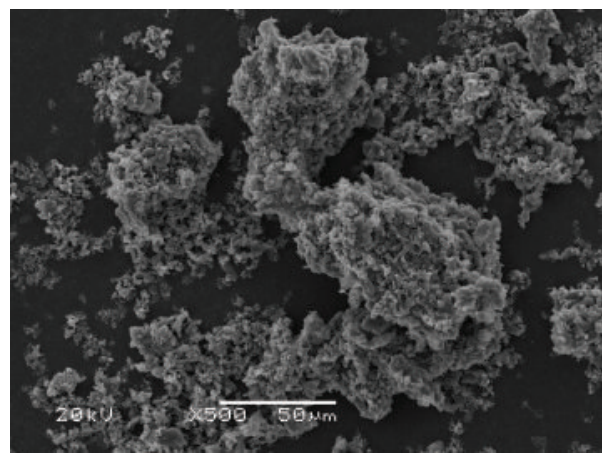

(a)

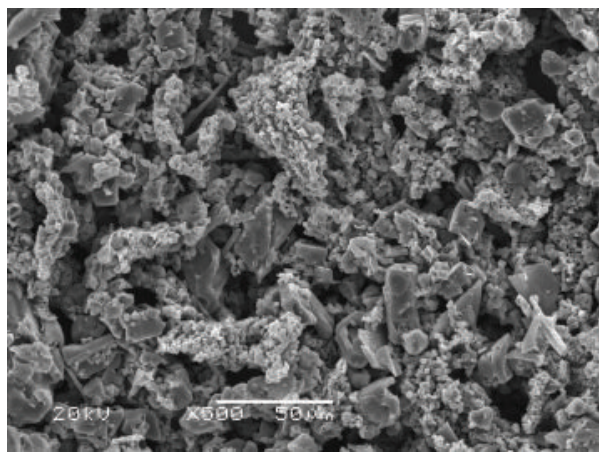

(c)

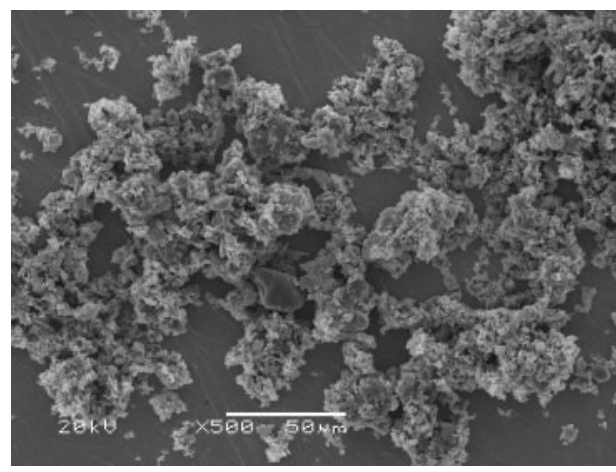

(e)

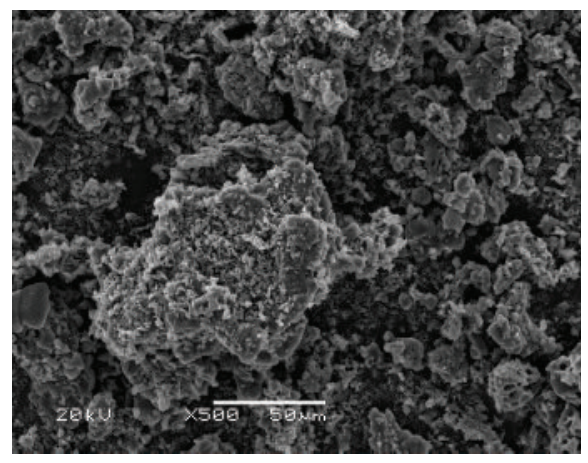

(b)

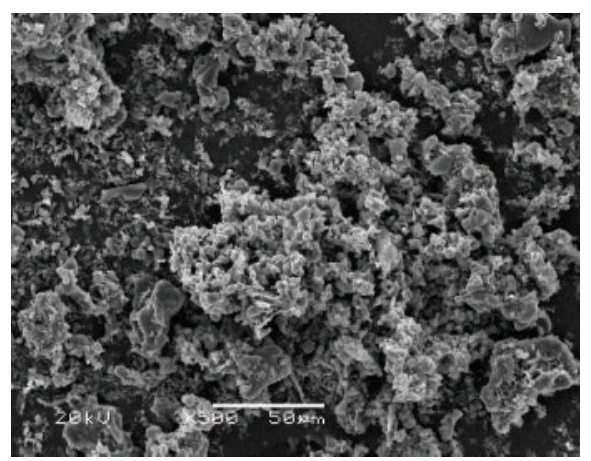

(d)

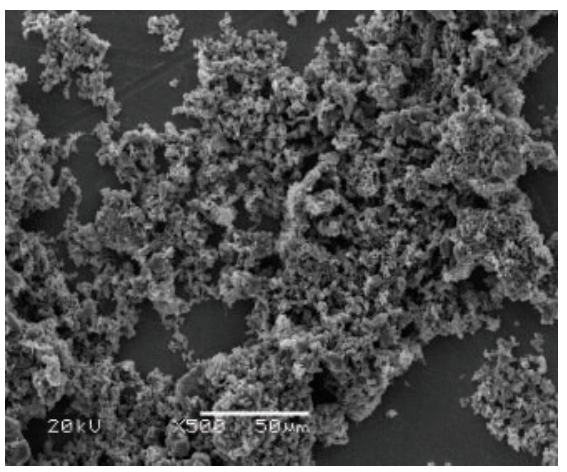

(f)

Figure 2: Morphologies of leached products obtained by salt-assisted SHS synthesis with different content of diluter. (a) $0 \% \mathrm{NaCl}$; (b) $10 \mathrm{wt} \%$ $\mathrm{NaCl}$; (c) 20 wt $\% \mathrm{NaCl}$; (d) $30 \mathrm{wt} \% \mathrm{NaCl}$; (e) 40 wt $\% \mathrm{NaCl}$; (f) 50 wt $\% \mathrm{NaCl}$.

TABLE 1: Melting points of reactants and products.

\begin{tabular}{lc}
\hline Reactants and products & Melting points $/{ }^{\circ} \mathrm{C}$ \\
\hline $\mathrm{NaCl}$ & 800.8 \\
$\mathrm{Mg}$ & 650.0 \\
$\mathrm{~B}$ & 2079.0 \\
$\mathrm{~B}_{2} \mathrm{O}_{3}$ & 450.0 \\
$\mathrm{MgO}$ & $2800 \pm 13$ \\
\hline
\end{tabular}

that the salt-assisted SHS technique is a liquid-liquid reaction mechanism.

3.2. Morphology, Particle Size Distribution, and Purity of Products Obtained with Different Contents of $\mathrm{NaCl}$. Figure 2 shows the morphology of leached products by adding different amounts of $\mathrm{NaCl}$ to the materials. From Figure 2(a), we can see that without $\mathrm{NaCl}$ there was a serious agglomeration phenomenon and a poor dispersibility between sample particles. The five samples of adding $\mathrm{NaCl}$ all contained a large amount of small particles and only a very few large particles. In terms of morphology, large particles showed the shapes of irregular geometry, while small particles exhibited similar spherical shapes. In Figure 2(a), large particles were about $5 \mu \mathrm{m}$, while small particles were within the range of hundreds of nanometers. With the increase of $\mathrm{NaCl}$ content, there were a decrease in the size of large particles in Figure 2(b) and an improvement in the dispersibility between particles. When the $\mathrm{NaCl}$ content reached $40 \%$, only a very few particles were within the size of about $1 \mu \mathrm{m}$, with others reaching submicron level. When the $\mathrm{NaCl}$ content reached $50 \%$, particles were uniform in size, most of which 
were within $0.5-0.8 \mu \mathrm{m}$. Only a small part of these particles exhibited nanosizes, with the presence of soft agglomeration phenomenon between the particles.

It indicates that the morphology and particle size could be controlled effectively through properly changing the addition of the diluter $\mathrm{NaCl}$.

Figure 3 shows the diagrams about size distribution of leached products obtained by salt-assisted SHS synthesis with different contents of diluter. Figure 3 was obtained by using Ipwin 32 software to make repeated statistics of SEM graphics first and then the graphics are drawn by the Origin software. Figure 3 shows clearly that with the increase of $\mathrm{NaCl}$ content the average particle size of products has a decreasing trend, with the increasing proportion of small-size particles. When $\mathrm{NaCl}$ increased from $10 \%$ to $40 \%$, the average particle size of boron powder decreased from $2.07 \mu \mathrm{m}$ to $0.8 \mu \mathrm{m}$. The average particle size of products decreased considerably. When $\mathrm{NaCl}$ increased from $40 \%$ to $50 \%$, the average size of boron power decreased from $0.8 \mu \mathrm{m}$ to $0.50 \mu \mathrm{m}$. The average particle size of boron powder decreased less considerably.

When $\mathrm{NaCl}$ increased from $0 \%$ to $50 \%$, the average particle sizes measured by laser particle size analyzer were $3.88 \mu \mathrm{m}, 3.22 \mu \mathrm{m}, 1.77 \mu \mathrm{m}, 1.73 \mu \mathrm{m}, 1.69 \mu \mathrm{m}$, and $1.64 \mu \mathrm{m}$, respectively. The reasons that average particle size increases compared with Figure 3 are as follows: (1) the samples were not saved in the inert gas, susceptible to oxidizing into $\mathrm{B}_{2} \mathrm{O}_{3}$ and liable to absorb impurities in the air, so that the particles increase; (2) hydration made particles increase in the process of ultrasonication.

From Figures 2 and 3, we can see that the diluter can effectively reduce the average particle size of products and weaken the agglomeration between the particles. The reason lies in that the salt-assisted SHS synthesis reaction is a liquidliquid reaction process; the addition of $\mathrm{NaCl}$ reduces the adiabatic temperature and slows down the rate of diffusion of the produced solid B particles in the liquid phase, which effectively avoids the rapid agglomeration of solid B particles. In addition, as the combustion synthesis is completed, the system will cool down. During the cooling process, liquid $\mathrm{NaCl}$ will first reach saturation and then precipitate, forming a coating layer on the surface of product particles and further preventing the continual agglomeration of $\mathrm{B}$ particles.

Comparisons of particle sizes between amorphous $\mathrm{B}$ powder produced with $50 \% \mathrm{NaCl}$ in this experiment with $\mathrm{B}$ powder produced by SB Boron are shown in Table 2.

From the comparison of $\mathrm{B}$ powder sample produced with $50 \% \mathrm{NaCl}$ and those produced by SB boron in Table 2, we can see that these indexes well satisfy the requirements of the composite propellant of solid rocket-ramjet engine [19]. Therefore, the use of salt-assisted SHS technique to produce B powder is of great theoretical value and practical significance.

An EDS analysis of six samples was made. The statistical results are shown in Table 3, from which we can see that after adding the diluter the purity of samples increased. The reason lies in the fact that the diluter reduced the adiabatic temperature of the reaction system and hence avoided the side reaction that may occur under high temperatures. When the addition of diluter increased from $10 \%$ to $50 \%$, the purity of leached boron powder barely changed. The prepared
TABLE 2: Comparison of particle sizes between amorphous B powder produced with $50 \% \mathrm{NaCl}$ and $\mathrm{B}$ powder produced by SB boron.

\begin{tabular}{lccc}
\hline Samples & $\begin{array}{c}\text { Samples in this } \\
\text { experiment }\end{array}$ & SB boron 90 & SB boron 95 \\
\hline $\begin{array}{l}\text { Average particle } \\
\text { size } / \mu \mathrm{m}\end{array}$ & $0.4 \sim 0.8$ & 1.0 & $0.8 \sim 1.0$ \\
B content/\% & $>96$ & $90 \sim 92$ & $95 \sim 97$ \\
\hline
\end{tabular}

TABLE 3: Element contents in leached products prepared with different contents of diluter.

\begin{tabular}{lcccc}
\hline $\begin{array}{l}\text { Samples } \\
(\mathrm{wt} \% \mathrm{NaCl})\end{array}$ & $\begin{array}{c}\mathrm{B}(\mathrm{wt} \%) \\
\text { EDS }\end{array}$ & $\begin{array}{c}\mathrm{O}(\mathrm{wt} \%) \\
\text { EDS }\end{array}$ & $\begin{array}{c}\mathrm{Mg}(\mathrm{wt} \%) \\
\text { EDS }\end{array}$ & $\begin{array}{c}\mathrm{B}(\mathrm{wt} \%) \\
\text { Chemical analysis }\end{array}$ \\
\hline 0 & 94.08 & 2.32 & 3.59 & 94.72 \\
10 & 96.09 & 0.15 & 3.77 & 96.02 \\
20 & 96.01 & 0.43 & 3.56 & 96.00 \\
30 & 98.22 & 0.25 & 1.53 & 97.96 \\
40 & 97.43 & 0.44 & 2.13 & 97.12 \\
50 & 96.26 & 1.16 & 2.58 & 96.16 \\
\hline
\end{tabular}

products contained only three elements, namely, B, O, and $\mathrm{Mg}$. The leached products contained over $96 \%$ boron powder, with other two elements less than $5.0 \%$, consistent with the results of chemical analysis. With the increase of diluter content, the content of element B showed the first rising and then declining trend, reaching the maximum value when the content of diluter was $30 \%$. However, the content of $\mathrm{O}$ and $\mathrm{Mg}$ elements changed in a trend opposite to that of element $B$, reaching the minimum value when the content of diluter was $30 \%$.

Figure 4 is an X-ray diffraction pattern of leached products. There is no diffraction peak of $\mathrm{B}$, indicating the $\mathrm{B}$ powder is amorphous. There are some unknown impurity peaks. The reason may be that after leaching B powder particles were in small size and had large specific surface area and high specific surface energy, susceptible to oxidizing into $\mathrm{B}_{2} \mathrm{O}_{3}$ and liable to absorb impurities in the air. Therefore, the produced $\mathrm{B}$ powder should be stored in the inert atmosphere.

Figure 5 is the diagram of selected area electron diffraction (SEAD) of leached products, indicating that the prepared $B$ powder is amorphous.

\section{Conclusion}

To prepare submicron B powder by the salt-assisted SHS technique was proposed in this paper. Calculation results show that the addition of diluter $\mathrm{NaCl}$ into the $\mathrm{B}_{2} \mathrm{O}_{3}-\mathrm{Mg}$ system can effectively reduce the adiabatic combustion temperature. With the increase of $\mathrm{NaCl}$ content, the adiabatic combustion temperature of the reaction system linearly declined. When $60 \% \mathrm{NaCl}$ was added, the adiabatic combustion temperature was $1799 \mathrm{~K}$, lower than $1800 \mathrm{~K}$, unsuitable for the selfpropagating reaction, which was consistent with results of experiment. 


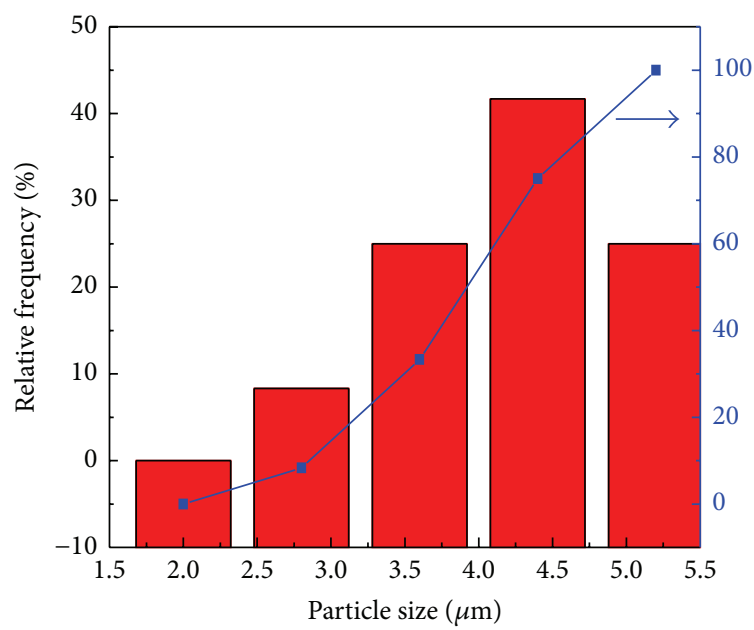

(a)

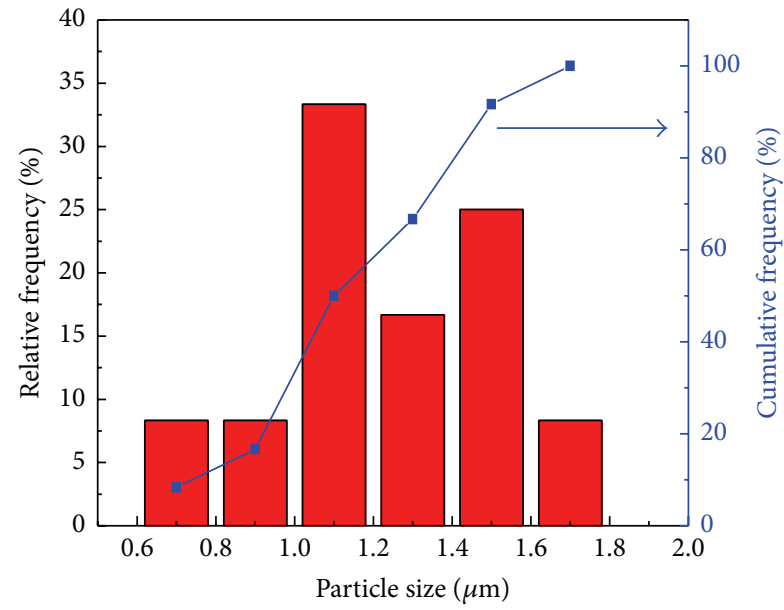

(c)

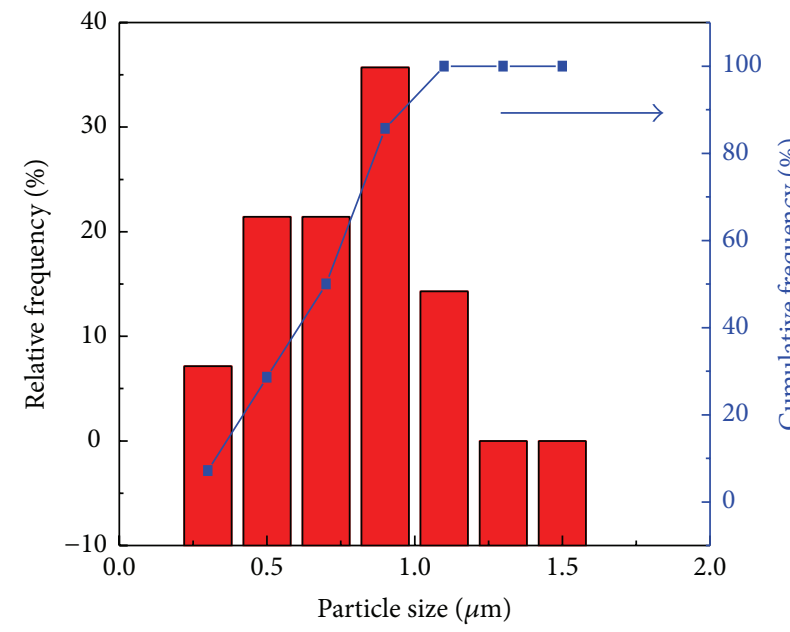

(e)

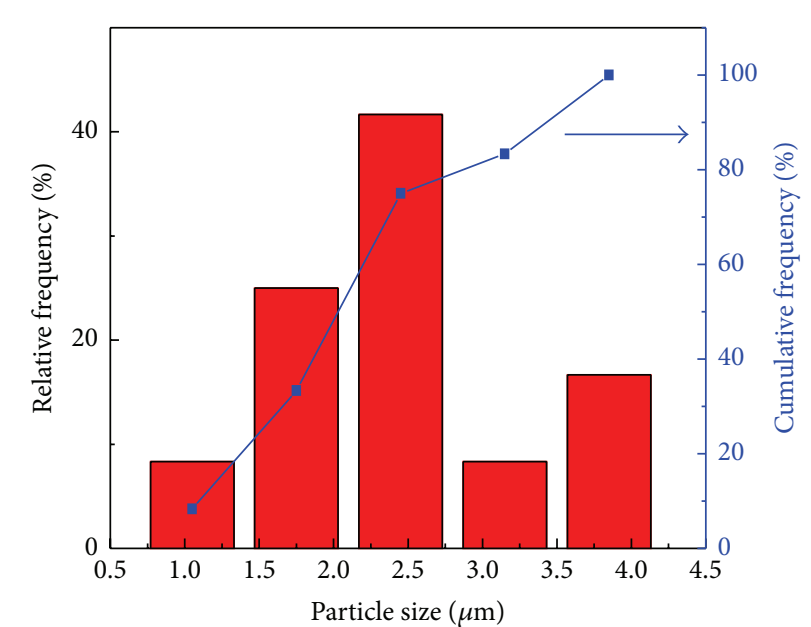

(b)

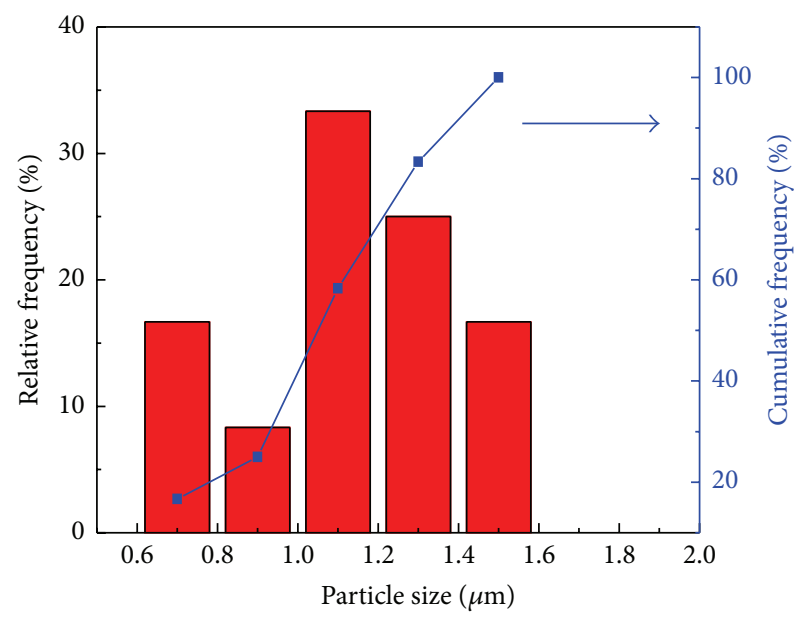

(d)

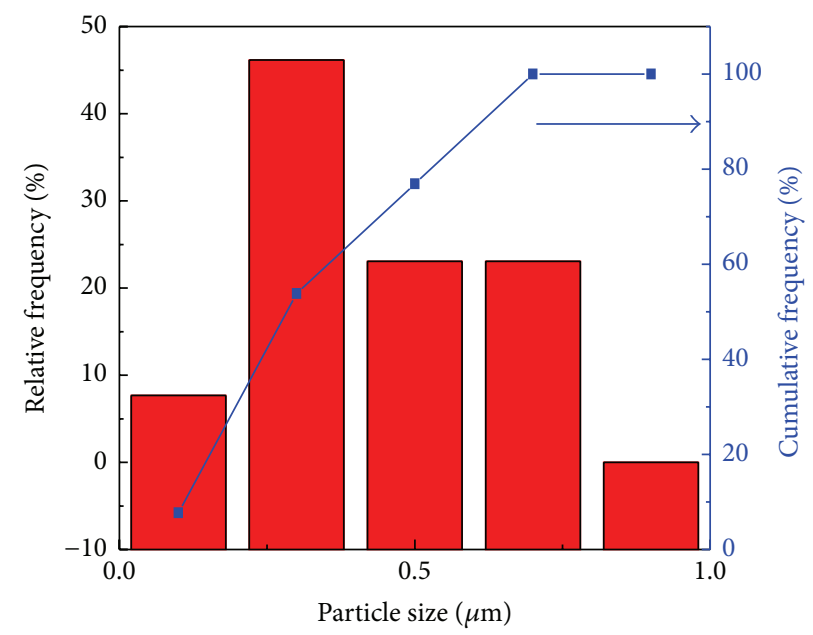

(f)

Figure 3: Particle size distribution of products obtained by combustion synthesis with different contents of diluter. (a) $0 \% \mathrm{NaCl}$; (b) $10 \mathrm{wt} \%$ $\mathrm{NaCl}$; (c) 20 wt $\% \mathrm{NaCl}$; (d) 30 wt $\% \mathrm{NaCl}$; (e) 40 wt $\% \mathrm{NaCl}$; (f) $50 \mathrm{wt} \% \mathrm{NaCl}$. 


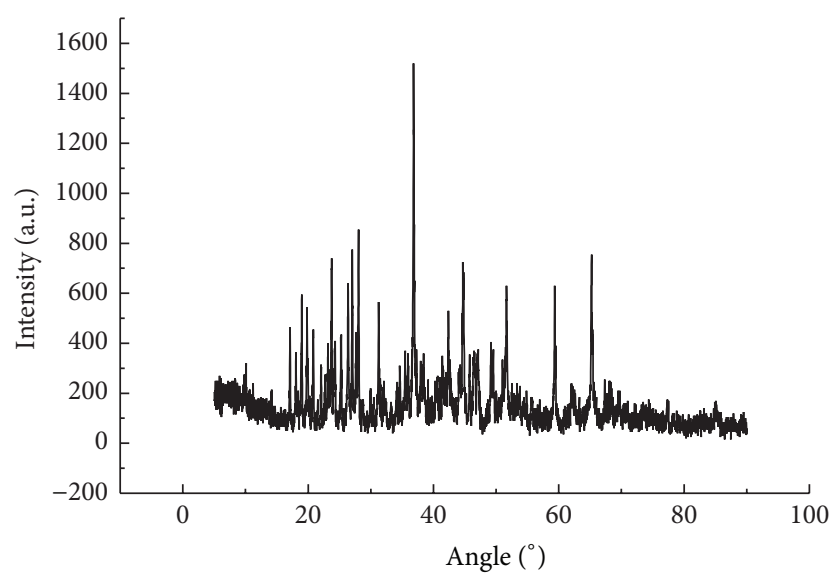

FIGURE 4: XRD patterns for leached boron samples.

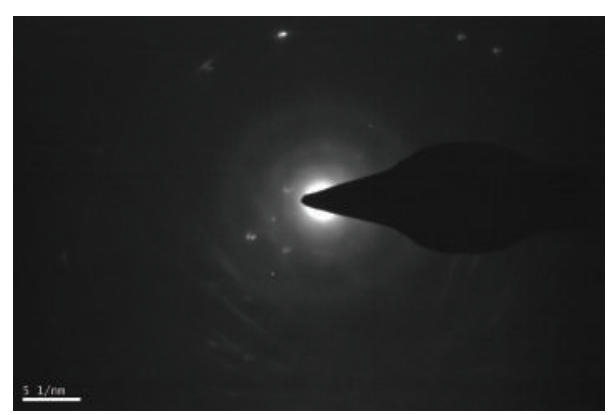

Figure 5: SEAD chart of leached B powder.

With the increase of $\mathrm{NaCl}$ content, the average particle size of leached products decreased. When $\mathrm{NaCl}$ content increased from $10 \%$ to $50 \%$, the average particle size decreased from $2.07 \mu \mathrm{m}$ to $0.69 \mu \mathrm{m}$. After adding the diluter, the product purity increased. When the content of diluter increased from $10 \%$ to $50 \%$, the purity of leached products was over $96 \%$.

The XRD and SEAD of products indicated that the prepared B powder was amorphous. The obtained B powder had small particle size and high activity and thus should be stored in the inert atmosphere.

This method could be further industrialization and become a common approach to prepare various inorganic materials. We hope that the present work is useful for the popularization and application of the amorphous boron powders.

\section{Conflict of Interests}

The authors declare that there is no conflict of interests regarding the publication of this paper.

\section{Acknowledgments}

This work was funded by National Natural Science Foundation of China (51164022) and the Natural Science Foundation B of Gansu Province, China (148RJZA003).

\section{References}

[1] C. L. Yeh and K. K. Kuo, "Ignition and combustion of boron particles," Progress in Energy and Combustion Science, vol. 22, no. 6, pp. 511-541, 1996.

[2] A. Haddad, B. Natan, and R. Arieli, "The performance of a boron-loaded gel-fuel ram jet," Progress in Propulsion Physics, vol. 2, pp. 499-518, 2011.

[3] X. J. Hao, E.-C. Cho, C. Flynn et al., "Synthesis and characterization of boron-doped Si quantum dots for all-Si quantum dot tandem solar cells," Solar Energy Materials \& Solar Cells, vol. 93, no. 2, pp. 273-279, 2009.

[4] M. Xie, D. Li, L. Chen, F. Wang, X. Zhu, and D. Yang, "The location and doping effect of boron in Si nanocrystals embedded silicon oxide film," Applied Physics Letters, vol. 102, no. 12, Article ID 123108, 2013.

[5] J. W. Hopewell, G. M. Morris, A. Schwint, and J. A. Coderre, "The radiobiological principles of boron neutron capture therapy: a critical review," Applied Radiation and Isotopes, vol. 69, no. 12, pp. 1756-1759, 2011.

[6] Z. Gao, N. I. Walton, A. Malugin, H. Ghandehari, and I. Zharov, "Preparation of dopamine-modified boron nanoparticles," Journal of Materials Chemistry, vol. 22, no. 3, pp. 877-882, 2012.

[7] G. Young, K. Sullivan, M. R. Zachariah, and K. Yu, "Combustion characteristics of boron nanoparticles," Combustion and Flame, vol. 156, no. 2, pp. 322-333, 2009.

[8] H. J. Jung, Y. Sohn, H. G. Sung, H. S. Hyun, and W. G. Shin, "Physicochemical properties of ball milled boron particles: dry vs. wet ball milling process," Powder Technology, vol. 269, pp. 548-553, 2015.

[9] P. Wang, S. Orimo, K. Tanabe, and H. Fujii, "Hydrogen in mechanically milled amorphous boron," Journal of Alloys and Compounds, vol. 350, no. 1-2, pp. 218-221, 2003.

[10] M. Song, H. An, and J. Zhao, "Prepartion of boron by moltenelectrolysis," Liaoning Chemical Industry, vol. 33, no. 8, pp. 469470, 2004.

[11] Z.-H. Dou, T.-A. Zhang, J.-C. He, and Y. Huang, "Preparation of amorphous nano-boron powder with high activity by combustion synthesis," Journal of Central South University, vol. 21, no. 3, pp. 900-903, 2014.

[12] Z.-H. Dou, T.-A. Zhang, and Y.-L. Wang, "Primary research on preparation of boron powder by self-propagating hightemperature synthesis with a stage of metallurgy," Journal of Northeastern University, vol. 26, no. 1, pp. 63-66, 2005 (Chinese).

[13] Y. Q. Wang, X. F. Duan, L. M. Cao, G. Li, and W. K. Wang, "Application of energy-filtering transmission electron microscopy to characterize amorphous boron nanowires," Journal of Crystal Growth, vol. 244, no. 1, pp. 123-128, 2002.

[14] S. O. Shalamberidze, G. I. Kalandadze, D. E. Khulelidze, and B. D. Tsurtsumia, "Production of $\alpha$-rhombohedral boron by amorphous boron crystallization," Journal of Solid State Chemistry, vol. 154, no. 1, pp. 199-203, 2000.

[15] L. Bao, J. Zhang, S. Zhou, and Z. Dou, "The effect of precursor boron nanopowder on the microstructure and emission properties of $\mathrm{LaB}_{6}$ cathode materials," Physica Status Solidi (C) Current Current Topics in Solid State Physics, vol. 9, no. 1, pp. 11-14, 2012.

[16] X. Liu, Research on mechanism of combustion synthesis of $\mathrm{Mg}_{2} \mathrm{Ni}$ and the hydrogen storage property of $\mathrm{Mg}-\mathrm{Al}-\mathrm{Ni}$ [Ph.D. thesis], Lanzhou University of Technology, Lanzhou, China, 2005.

[17] S. Han, Macroscopic quantity preparation and the formation mechanism of ultrafine ZrB2, TiB2, WC powders by salt-asssited 
combustion synthesis [Ph.D. thesis], Lanzhou University of Technology, Lanzhou, China, 2010.

[18] J. Y. Liang, C. Y. Che, and X. X. Liu, Inorganic Thermodynamics Data Hand-Book, Northeastern University Press, Shenyang, China, 1993.

[19] I.-M. Shyu and T.-K. Liu, "Combustion characteristics of GAPcoated boron particles and the fuel-rich solid propellant," Combustion and Flame, vol. 100, no. 4, pp. 634-644, 1995. 

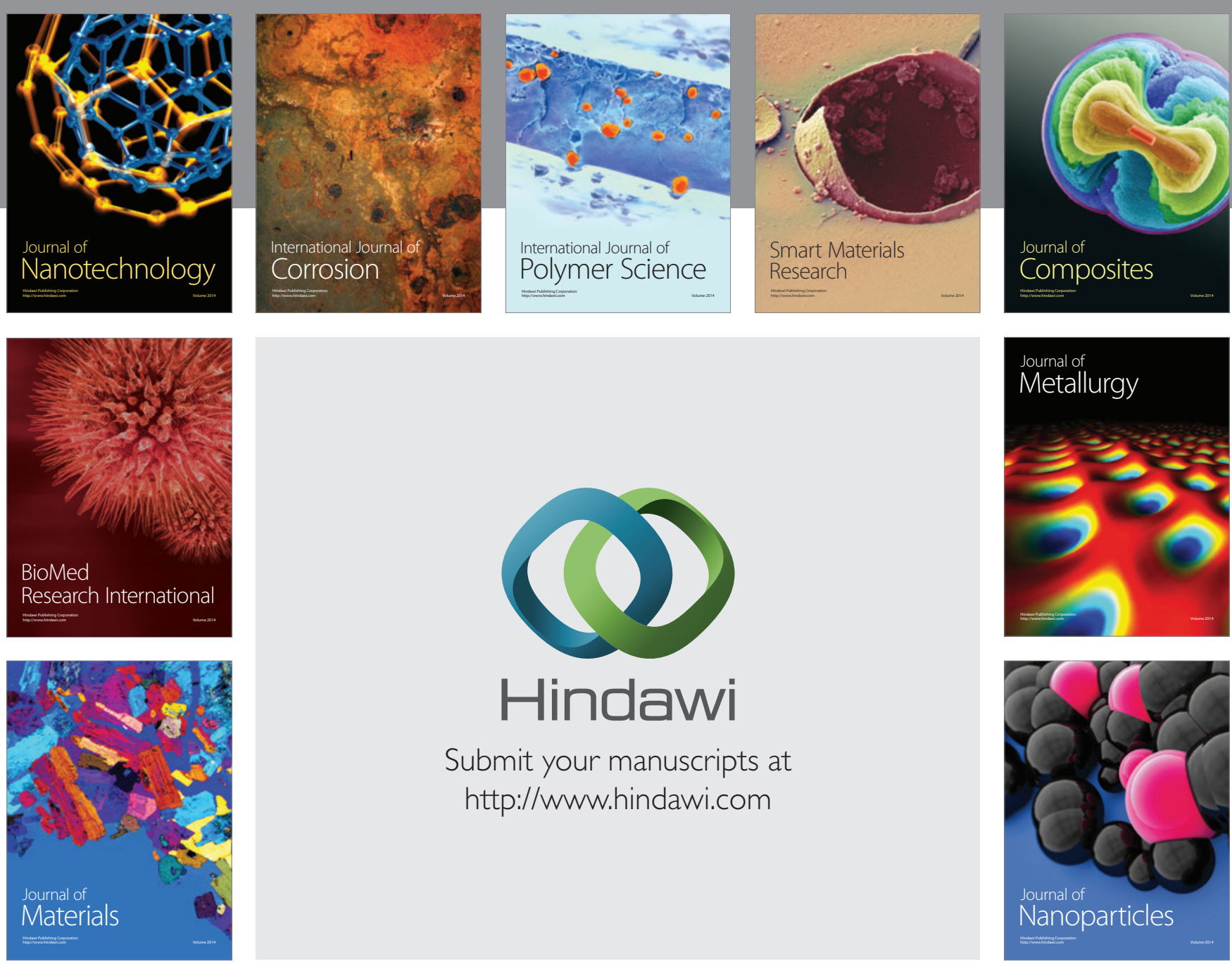

Submit your manuscripts at http://www.hindawi.com
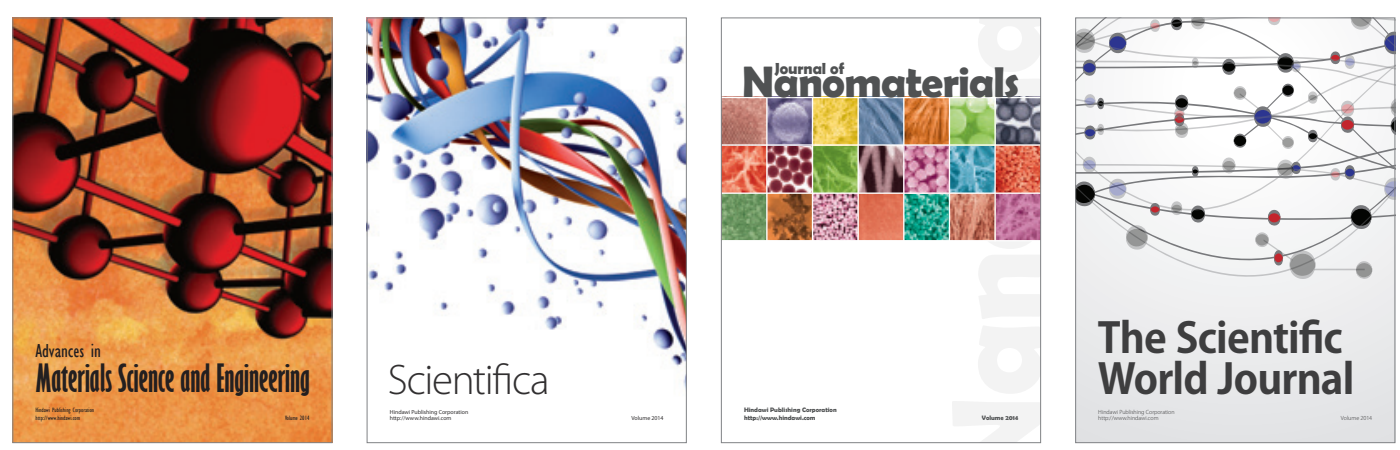

\section{The Scientific World Journal}
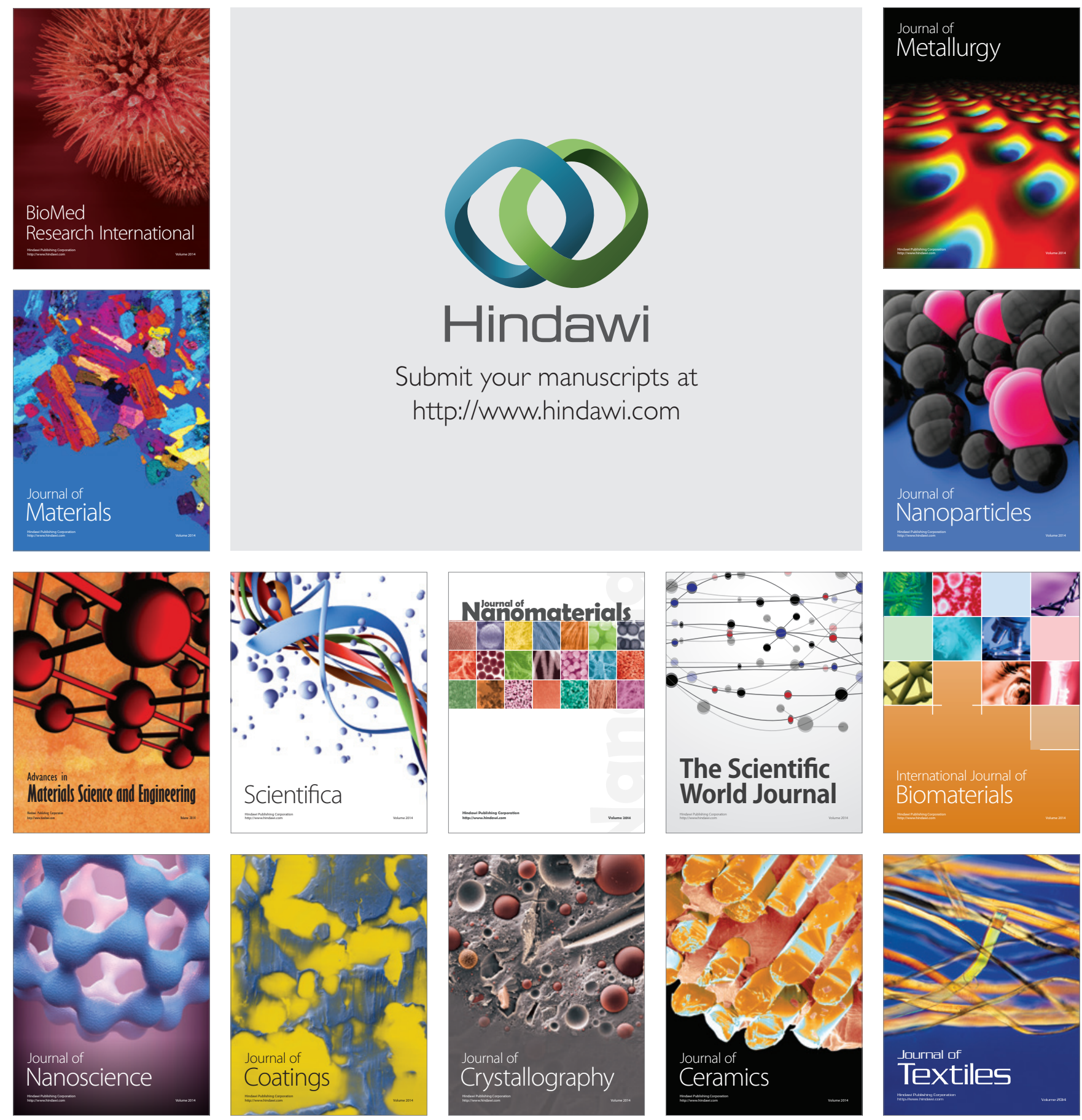